\title{
Quando o campo está na cidade: migração, identidade e festa
}

\author{
Luciana de Oliveira Chianca*
}

\begin{abstract}
Resumo: Trata-se aqui de apresentar algumas expressões simbólicas de atualização de uma identidade citadina de migrante, entre jovens citadinos brasileiros de origem socioeconômica desfavorecida. Através da observação de um dos mais importantes rituais da festa junina urbana em Natal - a quadrilha junina -, percebemos como suas versões "tradicional" e "estilizada" recuperam imagens estereotipadas do homem do campo, ora remetendo-se ao caipira imortalizado pelo Jeca Tatu, ora ao "matuto country" vestido em seda, veludo e cetim. De que modo essa produção identitária é percebida pelos seus atores e pelo conjunto da sociedade?
\end{abstract}

Palavras-chave: identidade; migração; festa; caipira; matuto.

$\mathrm{O}$ argumento central sobre o qual se constrói este artigo verifica-se na festa junina ${ }^{1}$ contemporânea da cidade de Natal, mas pode ser estendido a outras realidades sociais. Longe de abolir, inverter ou apagar as hierarquias sociais, o período festivo revela como essas distâncias são recuperadas e reorganizadas em um conjunto pertinente, que ritualiza e recria as distinções sociais cotidianas. Tal como é realizada hoje em muitas cidades do Nordeste do Brasil, essa festa - que já foi correntemente associada ao autêntico folclore brasileiro num discurso romântico identificado algures (Ortiz, 1992) - é festa popular e também política, econômica, mediática. A "festa de São João" é, na perspectiva de nossa análise, uma possibilidade de acesso à complexidade social na qual ela se inscreve. Estudá-la

\footnotetext{
* Doutora em Antropologia pela Université Bordeaux 2 (França) e professora do Departamento de Antropologia e do Programa de Pós-Graduação em Antropologia Social da UFRN.

1. Por "festa junina", entendemos o conjunto de manifestações festivas associadas aos santos católicos Antônio, João e Pedro. Neste artigo, às vezes empregamos a expressão "festa de São João" com o mesmo sentido, ou seja: para designar as festas do que também se convencionou chamar "ciclo junino".
}

"pela festa" permitiria revelar a universalidade de alguns dos seus aspectos simbólicos: mais proveitosa tem sido a perspectiva de compreender as construções sociais através da festa.

Apresentar a festa junina contemporânea de $\mathrm{Natal}^{2}$ implica reconstruí-la através de uma análise sócio-histórica e etnográfica, ressaltando sua relevância como elemento da memória individual e coletiva da maioria dos habitantes das grandes cidades: afinal não somos todos "filhos de migrantes?" Se a festa é presente no campo, nas pequenas e grandes cidades, em Natal muitos a identificam como "a festa do interior", "a festa do antigamente" e "o que há de mais puro e autêntico" no Nordeste.

\section{A festa "do antigamente"}

Por trás dessas afirmações correntes, podemos identificar dois níveis de discursos: um primeiro que revela a ligação da festa com a

2. Natal é a capital do estado do Rio Grande do Norte, onde foi realizada a pesquisa que deu origem a este artigo. Natal contava, em 2000, com uma população de 712.317 habitantes (fonte: Censo: 2000: www.natal.rn.gov.br/sempla/ paginas/estatisticas/informacoes.php). 
"autenticidade" e, em um outro nível, a sua associação ao universo simbólico representado pelo território do "interior". ${ }^{3}$ Ambas comunicam-se através do "antigamente", tempo de passado difuso mas constitutivo de uma memória construída no desenraizamento e na saudade daqueles que o deixaram um dia. O "interior" representa esse algures que "ficou pra trás"; ele territorializa (na festa, antes e também depois dela) uma experiência ambivalente, pois é simultaneamente um lugar/ tempo/ lembrança que se pretende superar, mas no qual permanecem laços de família, amizades ou recordações que fundamentam o presente na nova vida do migrante. Segundo a experiência migratória, esse lugar será mais ou menos rejeitado ou querido, rememorado ou idealizado, mas ele permanecerá o território "por excelência" da festa. Se a relação do festejante com o interior representa a ambigüidade dessa relação com o passado (familiar e pessoal), então de que maneira essa ambivalência se transpõe à festa? Que vínculos simbólicos ligam o interior ao São João? ${ }^{4}$

\section{A "festa do interior"}

Mesmo se as origens pessoais e as motivações da partida diferenciam as trajetórias dos migrantes, subsiste entre estes o sentimento de partilha de um passado comum que se realiza na construção de um vínculo solidário. Esse processo desencadeia a elaboração de uma

3. Citado nessas falas não como contraposição à capital dos estados, mas como terras distantes dos centros urbanos. "Interior" aqui é simbolicamente próximo de "sertão", "serra", "mato", "campo", lugares considerados selvagens antitéticos das cidades e urbes, cujo paradigma no Brasil são as capitais administrativas dos estados federativos e as grandes cidades política ou economicamente predominantes. Essa oposição binomial (forjada na capital e reproduzida de modo generalizado) propõe, em síntese, duas categorias "para pensar" o Brasil: o sertão e a costa (ver Sallas, 1999, p. 354).

4. Entre os vários aspectos que compõem a formulação desse "conceito festivo", vale a pena resgatar a formulação dos movimentos sertanista e folclorista, influências determinantes na construção do conceito coletivo desta festa no Brasil. De forte conotação romântica, ambos os discursos apresentaram uma construção idealizada do mundo rura que se contrapunha frontalmente ao país que então se urbanizava e industrializava em ritmo acelerado. A influência desses "projetos" na festa junina foi discutida em Chianca, 2004 e Chianca, 2006. memória social que recupera o "interior" como uma referência significativa e central, objetivada na composição de uma paisagem "rural", que compõe um "território do passado". Recuperando socialmente a experiência dos migrantes e de seus filhos em Natal, o "rural" conforta e tece "liens construits dans la déterritorialisation" (Offner \& Pumain, 1996, p. 166).

$\mathrm{Na}$ territorialização recomposta pelos natalenses, ${ }^{5} \mathrm{o}$ "interior" representa a categoria que se opõe à "capital" - ponto de chegada da maioria dos migrantes internos. ${ }^{6}$ Mesmo operando sobre limites espaciais imprecisos (Grunspan-Jasmin, 2001; Brun, 1989; Cavignac, 1997; Muzart-Fonseca dos Santos, 1997), essas fronteiras simbólicas são marcadas e perceptíveis: "l'on peut retrouver dans le discours une frontière, toujours variable, entre un lieu 'civilisé' et un lieu 'sauvage'” (Cavignac, 1997, p. 21). Essa mesma ambivalência selvagem/civilizado realiza um corte simbólico que se encontra na base das representações citadinas do "rural".

Como categoria difusa, o rural também revela um sistema de ambivalências no qual ele é espaço e testemunha de injustiças naturais, sociais e miséria, mas também de invernos chuvosos, abundância e festas alegres. Essas contraposições do rural organizam-se em dois sistemas classificatórios: um relativo à ordem social e outro a uma ordem natural. Elas encontram-se também na construção de uma identidade citadina do migrante tal como ela é apresentada na festa junina contemporânea de Natal.

\section{$O$ personagem central da festa}

Segundo Martins, a "elaboração dessa concepção citadina da vida rural vinha se esboçando havia mais de um século, pois, já a partir do começo do século XIX, tem início a formação de idéias e atitudes coincidentes com a urbanização, relativamente à diferença entre a vida rural e urbana" (Martins, 1975, p. 129). Com a difusão nas cidades de um modo de vida

\footnotetext{
5. O que é originário ou pertence à cidade de Natal.

6. Termo designando aqueles que realizam migrações no interior de um mesmo estado da federação.
} 
burguês, reforçam-se as diferenças entre as sociedades rural e urbana, sobretudo "relacionadas aos desempenhos culturais" (Silva, 1988, p. 246).

Sobre o "rural", uma série de representações ambíguas vai se associar ao campo e a "seu" habitante. Uma delas, a sertanista, ${ }^{7}$ representa as duas visões mais difundidas do sertão, misturando nostalgia com humor depreciativo e compondo uma imagem do "homem do campo", que se imortalizou através da figura do matuto e de seu homólogo caipira. ${ }^{8}$

Apesar do esforço metodológico de Antonio Candido em definir o caipira, a imagem que se imortalizou foi a do "Jeca Tatu" de Monteiro Lobato. ${ }^{9}$ Esta se torna a referência fundamental das definições pejorativas do homem rural nas cidades, através de uma representação literária ao mesmo tempo "injusta, brilhante e caricatural" (Candido, 1964, p. 82). A partir de sua criação, Jeca Tatu foi incorporado ao imaginário citadino e em seguida mais ainda com sua popularização por meio de uma publicidade de medicamentos amplamente divulgada no país: a do Biotônico Fontoura. ${ }^{10}$

Outros personagens ulteriores reforçam sobremaneira essa imagem dominante do caipira, como o Jeca Tatu de Mazaroppi, imortalizado em uma série de aventuras narradas em filmes realizados entre os anos 1950 e $1970 .{ }^{11}$ Chico Bento é outro herói caipira, oriundo das histórias em quadrinhos brasileiras de Mauricio de Souza

7. Movimento literário e artístico que "prolifera, sobretudo a partir do final da primeira década do século XX, privilegia[ndo] a forma tradicional do mundo rural centrado na grande lavoura, como forma social por excelência" (Martins, 1975, p. 131)

8. "Caipira" é do tupi kai'pira e tornou-se sinônimo de "matuto": "aquele que vive no mato" (Holanda Ferreira, 1999, p. 314).

9. Esboçado em Urupês (1918), no qual Lobato compara o caipira ao "sombrio urupê de pau podre, que vegeta no sombrio das matas".

10. Na qual são explicados os princípios fundamentais da higiene cotidiana, mostrando o perigo dos microorganismos para a saúde geral das pessoas. Segundo o site oficial de Monteiro Lobato, a tiragem desse folheto atingiu o recorde de "100 milhões de exemplares no centenário do escritor [sendo essa publicação] considerada a peça publicitária de maior sucesso na historia da propaganda brasileira" (www.lobato.com.br, acesso em: 25/4/2004).

11. Entre os quais destacamos Jeca Tatu (1959), Tristeza do Jeca (1961), O Jeca e a freira (1967) e Jeca contra o capeta (1975). publicadas a partir dos anos 1970: "para muitos de nós, brasileiros que vêm do campo, tal experiência teria um sabor todo próprio" (Silva, 1988, p. 255). Assim como ocorre com o cativante Jeca Tatu de Mazaroppi, Chico Bento revela toda a ambigüidade da representação citadina do homem rural. Bochechudo e simpático, ele é "obtuso, ignorante, incapaz de responder às mínimas exigências da escolaridade; de outro lado, identificamos nele dotes louváveis: amigo, filho amoroso, defensor da natureza, criança de bom coração e de boa índole" (Silva, 1988, p. 256). ${ }^{12}$

Pela carga simbólica que incorporam, os caipiras podem ser identificados ao trickster, mediador que "retient quelque chose de la dualité qu'il a pour fonction de surmonter" (Lévi-Strauss, 1974, p. 251). É por essa razão que os personagens matutos citados assumem todos essas ambivalências internas às suas próprias personagens. Assim, na festa junina de Belém, dois matutos diferentes opõem-se: o primeiro é o matuto cearense, que

reproduz todas as características do homem nordestino. Ingênuo, leal, ele não se desprende de suas raízes [e] além de tudo é cabra-macho e quer que todos saibam disso. [Já o segundo] caracteriza-se pela esperteza, astúcia, agilidade de raciocínio, profundo senso da ironia e do ridículo, pela capacidade de zombar dos outros e de si mesmo. (Moura, 1997, p. 223)

Essas definições do personagem "matuto" ou "caipira" indicam a instalação de uma distância simbólica definitiva nas representações citadinas cujo alcance atinge o personagem "selvagem" da festa junina, que se opõe claramente ao citadino/civilizado não somente pela sua maneira de vestir: eles são moralmente diferentes, pois seu universo e referências os opõem. ${ }^{13}$

Em Natal, cidade onde realizamos nossa pesquisa de campo sobre festas juninas e identidade de trabalhadores migrantes, as

12. Esse personagem teve sucesso entre adultos e crianças citadinos, inspirando inclusive outros personagens de histórias em quadrinhos, como o baiano Zé Pequeno, que representa um menino nordestino (ver Xaxado, jornal A Tarde: 21/6/2000).

13. A esse respeito ver o texto de Yatsuda, 1987. 
representações do caipira/matuto aplicam-se sem dificuldade aos trabalhadores e pequenos proprietários rurais. E mais precisamente aos migrantes internos, porque, para os citadinos, o matuto/caipira não é apenas "um rural", mas o representante desse universo junto ao citadino. Entre o interior (a "natureza selvagem") e a capital (a "urbe civilizada"), ele é o mediador do rural e do urbano.

\section{Marcando e conciliando oposições}

Reproduzindo uma realidade freqüente nos países de economia periférica, em Natal "le processus migratoire ne s'est pas accompagné d'une transformation des modes de production [ni] la création d'emplois dans les grandes villes réceptrices" (Domenach \& Picouet, 1995 , p. 52-53). Ele também não levou a um progresso positivo na situação social dos migrantes. Ao contrário, em pesquisa sobre migração no Rio Grande do Norte, Souza concluiu que "a mobilidade descendente foi mais acentuada em todas as classes" (Souza, 1980, p. 112).

Além do aspecto socioeconômico - que não é o único, mas marca de modo indiscutível a natureza dessas migrações -, há que se considerar as implicações ideológicas da construção simbólica do personagem festivo do matuto no quotidiano citadino, já que sua caricatura cristaliza os instrumentos da ascendência dos setores sociais dominantes sobre os trabalhadores urbanos de origem migrante. Aquela, exógena e estigmatizante, lembra o quanto é redutora a representação do migrante como um "ex-rural". No estado do Rio Grande do Norte, dados demográficos recentes revelam que nos anos 1970 - período de grande intensidade migratória interna - $89 \%$ dos migrantes que chegavam a Natal eram originários de zonas urbanas (Souza, 1980, p. 100). Ademais, devese levar em conta a heterogeneidade na urbanização das cidades e vilarejos "do interior" de onde são originários os migrantes internos: algumas delas são populosas e desenvolvidas.

Como convém aos excessos festivos em geral, no período junino esses personagens são recuperados como uma caricatura cujos defeitos são exagerados de modo pejorativo. Assim, a paródia mais comum do migrante incomoda não somente migrantes pobres como também alguns intelectuais que denunciam essa "noção ridícula ou idealizada do homem do campo" (Lins, 1977 , p. 155). Eles criticam a "hipocrisia dos professores" que ensinam na escola "esse cerimonial iníquo e altamente deseducativo que são as festas caipiras" (Lins, 1977, p. 155).

\section{Uma reconciliação conflituosa}

Considerado como "festa rural", o ciclo junino é, portanto, a mise en scène anual de um interior objetivado a partir da construção citadina do rural, mas também da memória subjetiva dos trabalhadores migrantes. Vendo seu presente freqüentemente como medíocre, eles idealizam seu passado e revivem (à sua maneira) "um estado originário" que os permite se projetar em seguida para um presente e um futuro valorizantes. É, portanto, em um espelho deformante e ambivalente que eles se contemplam. O São João é um dos raros momentos no qual eles podem legitimamente assumir suas origens e partir à procura desse "interior", atestando uma necessidade psicológica e existencial quasiuniversal.

Uma confirmação dessa idéia traduz-se na multiplicação das ofertas de viagens regulares ou turísticas para as principais cidades do interior nesse período, voltadas tanto aos antigos migrantes (que desejam aproveitar da ocasião da festa para retornar a suas cidades-natais) como a novos visitantes desejosos de conhecer uma "festa tipicamente interiorana". Nos períodos festivos, esses lugares recuados e esquecidos durante o resto do ano são bastante procurados e tornam-se destinos valorizados. ${ }^{14}$ Nesse momento, os olhares voltam-se com interesse para a identidade "rural" e para os migrantes, em tempo normal rejeitados pelo próprio

imaginaire national, avec son arsenal d'épithètes chargées de mépris, trahi(ssant) à l'envie la mauvaise opinion que l'on se fait, dans les villes, $d u$ interiorano. Ignorance, incapacité, inconstance, mauvaise volonté, roublardise, instabilité voire banditisme, tel

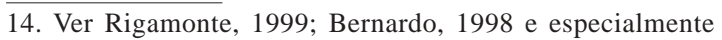
Menezes et alli, 1990. 
sont les traits constitutifs de son image de marque. (Morice, 1993, p. 350)

A grande maioria da população de Natal é composta de migrantes e de suas famílias, instalados há muitos anos em todos os seus setores e níveis da vida produtiva da capital, constituindo um verdadeiro sucesso de integração. Apesar dessa realidade, persiste na capital a idéia de que uma assimilação de sucesso implica a desaculturação do interiorano. Sua assimilação na vida citadina resultaria de um investimento pessoal e cotidiano para esconder suas origens, no qual eles "s'efforcent d'effacer le stigmate du paysan qui leur est toujours appliqué" (Cavignac, 1998, p. 39). Ao contrário dos migrantes ricos que dispõem de meios socioeconômicos e acesso ao poder de forma que possam reivindicar mais rapidamente e facilmente uma identidade natalense, os trabalhadores migrantes têm essa conquista dificultada: mascarar sua condição de migrante pobre tornase quase impossível para estes últimos, que encontram na cidade um campo de ação limitado essencialmente ao trabalho e às visitas entre pares. Assim, os "limites des dépenses vestimentaires et les stigmates physiques font obstacle à [leur] volonté de se mêler au reste de la population" (Morice, 1993, p. 359). Sua assimilação depende em larga medida do capital econômico e simbólico disposto pelo indivíduo.

No entanto, durante a festa junina, um novo dado se introduz nessa rede de trocas simbólicas: a capital procura e quer recuperar "o interior". Assim, parecem se interromper os conflitos identitários relativos à origem dos citadinos que estão presentes de modo subjacente durante todo o ano. Nesse momento, outras tensões identitárias ganham força e tornam-se mais visíveis como aquelas relativas às distinções de classe social e do acesso ao poder político, a educação, habitação, trabalho, consumo e mídia. Mesmo se o conjunto da cidade encena uma uniformidade social durante a festa ("somos todos filhos de migrantes"), salientando com orgulho uma identidade rural comum, os trabalhadores migrantes e seus filhos percebem que outras referências cotidianas sobrepõem-se à da origem. A pretensa igual- dade da festa nunca ultrapassa a "utopia festiva" (Duvignaud, 1991) sob pena de se subtrair ela mesma à vida social.

Embora se trate de um fenômeno complexo que implica uma negação e uma identificação simultâneas da identidade migrante, a festa junina projeta-os numa profunda afirmação identitária. Como detentores de um bom conhecimento da festa e de seus valores, durante a festa essas "pessoas do interior" são excepcionalmente percebidas num registro positivo, como proprietárias de um capital festivo simbólico, como consultores ou organizadores das festas. Os interioranos encarnam nesse momento uma autoridade indiscutível, já que conseguir animar uma festa numa rua, bairro ou cidade é um sinal de distinção social. Assim, para as populações que habitam os bairros desfavorizados - seja nos conjuntos habitacionais, bairros populares ou favelas -, a festa permanece como um momento precioso de afirmação socioidentitária, mas essa "inversão" merece uma relativização, porque, mesmo limitada à festa junina, ela não se faz sem reservas nem limites. ${ }^{15}$

É essa tensão identitária e política quotidiana que a festa junina metamoforseia em uma "brincadeira" leve, alegre e indiferente na qual os citadinos (migrantes ou natalenses) recriam o interior e seus habitantes. Longe de reafirmar essa imagem idílica e ingênua, cabe à reflexão socioantropológica analisar a cena festiva como um palco de conflitos e afirmação de identidades sociais. É por encerrar uma dinâmica que lhe é própria e dividida com o contexto no qual ela se inscreve que o São João de hoje não é mais a festa "de antigamente". É preciso compreender esse processo e perceber como essa transformação pode ser reveladora de novas formas de concepção do próprio universo rural do "matuto" que nele habitaria.

Hoje, este não é apenas um desdentado maltrapilho e iletrado, mas está presente na festa como um rico, próspero e bem sucedido agrobusinessman. Como explicar essa transformação? Pela influência da mídia e dos padrões estéticos americanos? Sem negar a parte que cabe à indústria cultural, esse processo é muito

15. Para o caso de Natal, discutimos essa questão em Chianca, 1999. 
mais complexo e dinâmico e envolve a imagem de si, constitutiva da identidade migrante.

\section{A quadrilha junina, dança da festa}

Antes de prosseguir na descrição do personagem matuto, parece importante explicitar para o leitor qual será o âmbito de investigação que tomaremos como referência da festa junina, sabendo que ela se processa em diferentes níveis culturais igualmente relevantes, como a música, a decoração, a culinária, as práticas religiosas, a sociabilidade e a dança. Dentre as várias danças ligadas ao período junino em Natal, algumas são dançadas o ano todo, como o forró, mas a quadrilha destaca-se das demais porque só é apresentada nessa época, tendo se tornado um símbolo dessa festa.

Originária de uma contradança de mesmo nome trazida ao Brasil pela corte imperial portuguesa, ela teve suas figuras e passos modificados ao longo do tempo e dos lugares em que foi sendo executada. A princípio, eram quatro ou oito casais que se organizavam em duas filas uma em frente à outra, com as quatro extremidades formando um quadrado - daí seu nome francês, quadrilles (em espanhol, cuadrilhas; em italiano, quadriglia). As quadrilhas pertencem às "danças baixas", assim chamadas porque nelas os casais fazem pequenos gestos cerimoniosos com os braços e pernas e quase não levantam os pés, evitando movimentos bruscos (Ribas, 1983). Nobre e cortês na origem, a quadrilha tornouse uma dança e um espetáculo popularizado e reinventado, marcando as festas de São João de todo o país.

As descrições dos viajantes da época do Brasil colonial apresentam as quadrilhas como danças praticadas nos salões ricos da corte, tanto na cidade quanto no campo, e nos falam que D. Pedro II era muitíssimo apreciador de quadrilhas. ${ }^{16}$ Ao longo dos anos, a quadrilha democratizou-se até se tornar uma dança praticada pelos menos abastados. Essa história pode ser compreendida quando sabemos que uma vez

16. Ele dançava na fazenda do Barão de Muriaé ou nos bailes solenes da Câmara Municipal do Rio de Janeiro. No mês de agosto de 1852, numa festa por ocasião do encerramento dos trabalhos do Senado, D. Pedro II teria dançado pelo menos nove das dez quadrilhas propostas (cf. Pinho, s/d). chegadas à corte do Rio de Janeiro as quadrilhas disseminaram-se, entrando nos ricos salões de Salvador, Recife e São Paulo em suas várias versões : "quadrilha de Julien", "quadrilha de Munsard", francesa, diplomática , napolitana, de lanceiros e quadrilha scottish.

Depois, e resumidamente, ${ }^{17}$ as danças dos nobres tornam burguesas-se: assim se iniciou a sua popularização, que no caso da quadrilha repete um processo freqüente na história, o qual a Europa conheceu no século XVI quando as danças palacianas restritas às cortes e à aristocracia transformaram-se em danças de salão da alta e média burguesias. No Brasil, ocorreu o mesmo fenômeno, com o conjunto da população reproduzindo à sua maneira a dança das classes altas, "recebendo adaptações adoráveis que foram depois retomadas pela burguesia" (Andrade, 1989, p. 414). Mas por que e como essa dança se tornou uma importante referência da "festa do interior"? 18

O que explica esse deslocamento simbólico é o fato político e as implicações culturais da mudança de poder do Brasil republicano, quando os costumes do período colonial e imperial foram desprezados pelas camadas burguesas urbanas e citadinas. Provavelmente nesse momento a quadrilha teria sido abolida das festas dos citadinos ricos, continuando a ser dançada pela população mais distante dos grandes centros urbanos, os interioranos - geograficamente e simbolicamente defasados com suas danças já "fora de moda". ${ }^{19}$ Até o presente, os dançarinos de quadrilha fantasiam-se de "rurais" de uma forma pejorativa e caricatural. O que hoje conhecemos como quadrilhas tradicionais/matutas apresentam essa versão da dança nobre na origem e que se tornou popular.

Nesse modelo de quadrilha, duas filas de casais matutos alinham-se frente a frente seguindo as ordens do animador da quadrilha (ou "puxador"), em passos preestabelecidos e fazendo uma seqüência de passos ensaiada

17. Essa história foi desenvolvida em Chianca, 2004 Chianca, 2001.

18. O "mistério da quadrilha" é melhor explicado em Chianca, 2004

19. Essa hipótese pôde, inclusive, ser verificada no contexto de Natal. Sobre isso, ver Chianca, 2006. 
antecipadamente ou não. Essas duas filas não competem entre si, mas compõem um conjunto com evoluções ordenadas e harmonizadas.

Os dançarinos das quadrilhas tradicionais são todos "matutos", reunidos para um casamento na roça, no qual se representa o enlace (quase) forçado de um matuto que engravidou a noiva e que tenta fugir, mesmo na presença das autoridades religiosas e da lei. O pai da noiva consegue capturá-lo nas suas tentativas desesperadas, e os convidados se deliciam escutando o diálogo entre ele, o pai da noiva, o padre, o delegado e a noiva, através de um texto malicioso que revela as tensões e conflitos em jogo nesse matrimônio. A quadrilha é então o baile da festa de casamento dos noivos - personagens principais da quadrilha, junto com o padre e o juiz (ou policial). Uma quadrilha também pode ocorrer sem um casamento matuto, mas já em 1843 foi descrita por Melo Morais Filho como uma das danças de uma festa de casamento. ${ }^{20}$

\section{Como ser matuto/caipira: algumas técni- cas corporais}

Desde os anos 1930, o modelo do matuto definiu-se pela simplicidade vestimentar. Esse estado revelador de privações econômicas só acentua as associações citadinas correntes, aproximando, como vimos, os matutos e os migrantes economicamente desfavorecidos e sublinhando assim um estado de fraqueza social que ninguém desejaria assumir.

Assim, a escolha das roupas festivas é informada por essa precariedade, sendo a chita o tecido-chave da roupa matuta. Ora, também na escolha dos tecidos, a hierarquia social imprime sua marca, sendo a popelina e a viscose preferidos pelos clientes mais abastados ${ }^{21}$ (a chita é conhecida pelo seu baixo custo, correspondendo a sua pouca qualidade). De uma maneira geral, a vestimenta dos matutos segue o estereótipo citadino do homem do campo, ao qual se atribui por ocasião das festas e eventos sociais o gosto das cores fortes e disparates chamadas "alegres" e "vivas". Os matutos

20. Para maiores informações acerca das quadrilhas matutas, seus personagens e casamento, ver Chianca, 2001 e Chianca, 2004.

21. Jornal Tribuna do Norte, 20/6/1996. masculinos usam uma roupa pouco variada e muito despojada, composta de calça, na qual se improvisa um remendo confeccionado a partir de restos de tecido, e de uma camisa unicolorida, quadriculada ou xadrez, recosturada com remendos. Sobre a cabeça, um chapéu de palha ou feltro e nos pés sapato aberto de "rabicho" 22 ou sapato de couro. Em torno do pescoço, alguns matutos usam um lenço vermelho em geral amarrado no peito.

As matutas usam um vestido ou saia com blusa de babados e rendas sublinhando suas formas femininas. Sobre esse último elemento estético, há um grande cuidado com os excessos, que seriam considerados vulgares e de maugosto, sem corresponder à suposta moral das senhoritas e senhoras "do interior"; vaidosas, sim, mas discretas e honestas! Os acessórios femininos são bastante apreciados: pulseiras, anéis, colares, brincos de orelha, fitas no cabelo. Nos pés, sandálias em tecido ou couro de "rabicho". Elas usam cabelos presos ou tranças sob seus chapéus de palha, que às vezes são sintéticas, louras ou negras: a matuta típica deve ter cabelos longos.

A maquiagem também é alvo de muito cuidado e participa da paródia em torno do matuto: nela são simulados dentes em falta, pintados de preto ou cicatrizes grosseiras nos rostos e corpos. Sobrancelhas, barbas e bigodes são alargados e reforçados com lápis pretos para dar uma imagem mais "selvagem" do matuto: os pêlos são considerados em função de uma simbologia ligada à fertilidade, como "manifestation de la vie végétative, instinctive et sensuelle" (Chevalier \& Gheerbrant, 1944, p. 796), e visam recriar um estado de natureza que o modelo festivo citadino esforça-se em lembrar com humor.

Nas matutas, essa caracterização é mais leve e se limita às vezes a pintar de preto alguns dentes e a esboçar no rosto algumas imperfeições vegetativas e da natureza, como marcas/ sinais de pele. A maquiagem de olhos, lábios e bochechas é forte e feita com cores vivas.

Além de confeccionar a sua roupa matuta especialmente para a festa, uma segunda possibilidade consiste em recuperar roupas usadas:

22. Corte de couro laminado, bastante macio e confortável. 
as festas juninas marcam o único momento do ano em que vestimentas de pais e avós são publicamente recuperadas, sendo que tal recurso valoriza a qualidade da fantasia de matuto. Estamos diante de mais um indício da relação dessa festa com um passado que se deseja revisitar: de fato, a vestimenta é o elemento mais essencial na preparação de uma viagem, e muitas vezes o único bem que se transporta quando de uma migração. Retomar as roupas de família parece ser um modo de recuperar sua identidade de migrante a fim de melhor ultrapassá-la no contexto derrisório da festa. Sem exaltar essa identidade pré-migratória, o ritual permite que ela seja reexperimentada, para ser em seguida desdenhada - assim como a esse passado definitivamente abandonado.

Antigos ou fora de moda, esses elementos objetivam construir uma vestimenta reintegrada na leitura citadina e festiva atual. Dessa forma, o patrimônio vestimentar de uma família é recuperado como objeto de riso, em uma reconstituição da qual toda a família participa (dessa vez) se divertindo. Mal coordenadas entre si e mal cortadas para os que a portam, as roupas reforçam a imagem hegemônica do matuto, segundo a qual o migrante não está adaptado à vida na capital, esta última reclamando um certo savoir-vivre e o respeito aos códigos vestimentares característicos da urbanidade.

Para a juventude descendente de migrantes, tal caricatura lembra que o interior idealizado não é necessariamente enobrecedor e que é preciso mantê-lo a uma boa distância do presente citadino. Através desse jogo de recuperação e distanciamento, a ideologia dominante tenta provar o quanto a migração foi acompanhada por uma promoção social e cultural das famílias em questão.

É interessante notar como a sociedade urbana recupera a dualidade natureza/cultura na vestimenta do matuto durante a festa junina. Apresentado como um semi-selvagem, ele é inadaptado às práticas corporais citadinas. Essa inadaptação à moda e ao "bom gosto" é também sublinhada na visão dominante do matuto em Natal. No entanto, enquanto alguns grupos reivindicam essa imagem, outros a questionam e só recuperam alguns traços dessa estética considerada excessivamente grosseira. Assim, segundo o projeto em questão, apenas alguns desses traços serão recuperados a fim de dar uma imagem menos caricatural ao matuto. ${ }^{23}$

\section{O movimento "estilizado"}

Embora a data exata de sua aparição seja objeto de polêmica, ${ }^{24}$ em Natal os grupos estilizados apareceram a partir de meados de 1990, seguindo um processo lento e progressivo de transformação interna da dança tradicional que atinge uma maior visibilidade a partir de 1995 , nos grandes concursos de quadrilha promovidos pela prefeitura e pelas subsidiárias locais da TV Globo e do SBT. A real paternidade do movimento parece difusa, sendo constituída a partir de diversos grupos que teriam recorrido de modo pontual e simultâneo a lantejoulas, paetês, novos tecidos, maquiagem, roupas e depois novas coreografias e temas inovadores na apresentação.

Uma das fontes dessa nova estética unicamente vestimentar, de início - parece ter sido o programa televisivo cotidiano chamado Xou da Xuxa. ${ }^{25}$ No mês de junho esse programa recebia, para apresentação, grupos de quadrilha escolares da Região Sudeste. De fato, os grupos que então se faziam conhecer em rede nacional não reproduziam os cânones do padrão festivo tradicional (vestimentar, inclusive) de Natal, mas exibiam roupas confeccionadas com tecidos caros, vestidos longos de cores claras, com rendas e ornamentos.

Ora, se esse programa de televisão tem sua importância na evolução das quadrilhas da cidade, sua ascendência não é exclusiva nem determinante, mesmo se freqüentemente ele é evocado por aqueles que desejam associar esse movimento à massificação ideológica promovida pelos meios de comunicação. O que nos permite

\footnotetext{
23. É nessa linhagem que se inscrevem os grupos de quadrilha estilizados, assim como os "matutos revisitados" e os "estilizados light", analisados noutro trabalho (Chianca, 2004)

24. O pioneirismo é objeto de reconhecimento, prestígio e autoridade. Por isso, em Natal, vários grupos reivindicam a gênese desse movimento, entre os quais podemos citar as quadrilhas Sassaricando e Arriba a Saia, ambas da zona norte da cidade.

25. Difundido nacionalmente pela Rede Globo de Televisão nos anos 1980 e 1990.
} 
relativizar sua importância é a grande variação de suas fontes inspiradoras e a variada gama de expressão contemporânea da dança, como veremos. Outro dado de grande relevância é o fato de que, apesar da importância da mídia, as quadrilhas "matutas" permanecem majoritárias entre os "grupos espontâneos" e "de espetáculo", que constituem de modo indiscutível as principais e mais fundamentais expressões festivas da dança. ${ }^{26}$ É apenas junto aos grupos de competição que o modelo estilizado encontra repercussão e difusão.

A partir de sua aparição em grande escala, nos concursos (ou festivais) de quadrilhas, os grupos estilizados causaram muita polêmica por parte de jornalistas, folcloristas, intelectuais e demais autoridades "cultas" da cidade. O debate sobre essa nova expressão da dança atingiu o conjunto da sociedade natalense, provocando discussões acaloradas acerca da legitimidade do emprego dessas novas cores e materiais localmente insólitos, tais como os vitrilhos e tecidos "exóticos", como o veludo e o cetim. Podemos perceber a amplitude desse mal-estar quando um jornalista publica uma crônica em importante jornal local, em 1996, dizendo que essas danças mais pareciam "russas, ucranianas". Ele reprovava os dançarinos por quererem parecer o que não são: "já se viu um sertanejo dançar assim?", interrogava-se. ${ }^{27}$ Outro aspecto relevante nesse debate é que nenhuma dessas autoridades desejava distinguir as quadrilhas estilizadas como uma "nova dança". Sem essa emancipação, elas permaneceram associadas às quadrilhas tradicionais, às quais elas sempre foram comparadas.

Sua situação assim é das mais desconfortáveis: enquanto os conservadores a recusam como "degradação da tradição", os intelectuais de esquerda denunciam sua natureza "massificada", seus promotores como "cúmplices" e seus praticantes como "vitimas da alienação cultural" que ela representaria.

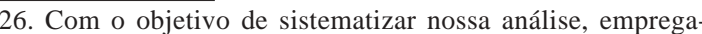
mos uma classificação tipológica dos grupos de quadrilha contemporâneos de Natal, dividindo-os em três tipos: 1) os espontâneos; 2) de espetáculo; 3) de competição. Essas categorias encontram-se definidas e explicitadas em Chianca, 2004.

27. Jornal Tribuna do Norte, 8/6/1996.
}

Se, com efeito, ela se beneficiou desde seus primórdios de uma difusão mais ampla por parte da televisão, também contou com a simpatia de grande parte do público, sendo assim progressivamente identificada como uma filha bastarda que quer "parecer o que não é". Essa visão negativa foi empregada para combater esses grupos, que teriam perdido suas características "autênticas" para se tornar uma miscelânea de inspirações culturais e artísticas diversas. Esse pavor alarmista de uma "perda cultural" expandiu-se entre os conservadores de todas as camadas sociais, reunindo a população mais nostálgica da quadrilha matuta que, entretanto, nunca desapareceu.

Diante dessa resistência, outros aspectos vêm sublinhar a amplitude dos conflitos socioculturais em jogo nessa evolução da dança. Em primeiro lugar, a origem social dos grupos de quadrilha estilizada: visivelmente mais numerosos na zona norte, setor de ocupação urbana ocupada pela população oriunda de migração interna mais recente - a partir dos anos 1970. De fato, a quadrilha estilizada era dançada pelos "primos pobres" dos citadinos "ricos". Junto ao mal-estar cultural já evocado, vem se acrescentar esse elemento de conflito identitário de bases socioeconômicas.

Se o conjunto das práticas contemporâneas da festa foi articulado por uma elite socioeconômica composta por intelectuais, folcloristas, educadores e jornalistas, como aceitar que a nova dança fosse obra desses jovens migrantes? É verdade que, pela sua familiaridade com o "rural" e os "matutos", esses jovens migrantes deveriam ser reconhecidos como autoridades festivas, "refazendo o rural na cidade". Mas, se assim fosse, como amparar a definição tradicional da festa? Ora, a história social da festa em Natal sublinha as fontes citadinas e elitistas da quadrilha, ${ }^{28}$ da qual d. Gurgel, um dos mais importantes folcloristas do estado, ${ }^{29}$ admite a origem burguesa. Para ele, a quadrilha é uma dança de pessoas da alta sociedade, tendo "descido da elite para o povo". ${ }^{30}$

\footnotetext{
28. Ver Chianca, 2006; Chianca, 2004.

29. Presidente da Comissão Norte-Riograndense de Folclore (em 2006).

30. Jornal O Poty, 22/6/1980.
} 
Popularizada em Natal desde os anos 1950, ela teria fugido ao controle dessa elite: foram os migrantes e seus filhos que a conservaram, reproduziram-na e reinventaram-na como uma das manifestações mais populares da festa junina contemporânea em Natal. Nesse campo político cultural de grande significação simbólica, a ação dos grupos de quadrilha não se resume ao consumo de alguns produtos culturais, mas compreende a concepção e a execução de um projeto coletivo. Ela difere, assim, do forró, que conheceu também muitas transformações na sua forma, mas que permaneceu, em grande escala, dependente dos circuitos da indústria cultural $^{31}$ - raríssimos são os grupos de quadrilha que conseguiram se inserir num circuito de apresentações remuneradas.

O fato é que, quando ganharam visibilidade em meados dos anos 1980, esses grupos foram imediatamente comparados com os "grosseiros" e "deselegantes" matutos, da dança tradicional. O confronto reforçava-se, sobretudo, porque, em um primeiro momento, a forma convencional e a estilizada concorriam em igualdade de condições nos concursos de quadrilhas. Sua especificidade foi rapidamente reconhecida, não só pelos críticos, mas também pelo público e, principalmente, pelos organizadores dos festivais: atentos a sua originalidade estética, eles lhes propuseram uma "modalidade" à parte nos concursos.

Conscientes da distância estética e - a nosso ver - simbólica que os separava dos estilizados, os grupos matutos apoiaram essa cisão, que beneficiou sobretudo os grupos estilizados: livres da tradição, eles investiram na invenção e na criatividade, propondo um espetáculo original a cada apresentação. Outros grandes beneficiados serão os promotores dos concursos que puderam, assim, promover produções artísticas de grande expressividade e riqueza estética, sem a contrapartida de investimentos.

Com sua liberdade assegurada pela independência do modelo tradicional da dança, os grupos estilizados seguiram num ritmo de transformações relativamente regular e suficientemente estável para que possamos falar de um

31. A trajetória do forró desde sua "invenção" até suas formas contemporâneas pode ser encontrada em Chianca, 2006 estilo próprio da quadrilha contemporânea. A natureza dessa evolução pode ser encontrada a partir de alguns aspectos de suas apresentações, como encenação, coreografia, alegorias, personagens e música das quadrilhas estilizadas. ${ }^{32}$

Para as finalidades deste artigo, deter-nosemos sobretudo na apresentação do personagem da quadrilha, o matuto, tal como ele é representado nas novas quadrilhas estilizadas de Natal.

\section{"Matutos, mas de luxo"}

Desde a época em que surgiu, o que distingue uma quadrilha matuta/caipira/tradicional de uma quadrilha estilizada é o efeito espetacular e vistoso desta última, que se revelava sobretudo pela atenção especial dedicada ao corte, às cores e ao acabamento das roupas empregadas na dança.

Em sua autodefinição, há que se salientar que os dançarinos de quadrilha estilizada não se identificam mais como "matutos", ou "caipiras", mas como "dançarinos", traduzindo assim seu desejo de afirmação e de um reconhecimento mais valorizante da sociedade e extrapolando o clichê de "homens do campo" - também sinônimo de "tradicional". Eles operam, dessa maneira, em uma transição entre a identidade de seus pais e as suas próprias, "déchirés entre l'expression de leurs racines et leur désir de vivre comme tout chacun" (Domenach \& Picouet, 1995, p. 85).

É no interstício entre os símbolos citadinos e rurais que eles reproduzem uma nova representação citadina do homem rural: destacandose da recordação (geralmente dolorosa), eles desejam integrar o "agricultor" na nova condição de "produtor agrícola" que usa o trator ao invés do arado e da enxada, produzindo melhor, "sem sujar as mãos" e roupas. Para recompor essa personagem festiva, costureiros e figurinistas ${ }^{33}$

\footnotetext{
32. Essas questões são discutidas em Chianca, 2004, tanto para os grupos estilizados quanto para os tradicionais.

33. O projeto estético-cultural de um grupo de quadrilha, sua elaboração e mise en scène foram descritas em nossa tese, na qual detalhamos também o papel do conjunto de especialistas envolvidos numa quadrilha, como sonoplastas, iluminadores, costureiros, coreógrafos e auxiliares (ver Chianca, 2004)
} 
recorreram a elementos estéticos rurais provenientes da Europa e da América (do Norte, Sul ou Central). Esse conjunto bricolé sintetiza um simbolismo que pode ser percebido nas roupas dos seus dançarinos e em uma certa postura corporal.

Para os rapazes, a principal referência de uma ruralidade vestimentar é a do cowboy norteamericano, sempre de chapéu, botas e cinto no estilo "texano". Às vezes, o gaúcho argentino inspira seus criadores, com bombachas. As dançarinas usam vestidos longos com camadas superpostas de tecido - que elas levantam às vezes em plena apresentação, mostrando deliberadamente suas roupas íntimas -, reproduzindo o movimento das dançarinas de frenchcancan do far-west, conhecido através da filmografia norte-americana. Seus corpetes encontram inspiração nessa referência, ou talvez no imaginário sobre as camponesas européias. Esses fragmentos do que constitui para eles um "exotismo rural" são a base da concepção local do "homem rural universal".

A constância do modelo norte-americano nessa estilização do personagem junino pode ser compreendida através da globalização cultural representada no Brasil pela televisão. Sua influência também foi reforçada pelos rodeios, que difundiram a partir dos anos 1980 uma estética vestimentar particular. ${ }^{34}$ Mas a estética "rural universal" não se reduz ao cowboy: ela se compõe também no recurso a tecidos, acessórios e adornos vindos de "outros universos", suficientemente distantes dos padrões locais para reforçar a preferência dos grupos estilizados pelos padrões não-locais - como veludos, cetins e cristais. O conjunto de dançarinos revela também exigências pouco habituais em matéria de cuidados corporais e para as suas apresentações preparam de modo excepcionalmente zeloso suas unhas, cabelos, pêlos corporais e maquiagem. O novo dançarino não é um matuto, mas alguém que se cuida e sabe se preparar. Tudo nele deve marcar sua oposição com os dançarinos da outra modalidade.

34. Marcada por calças jeans, cintos de couro largos com grandes fechos metálicos, camisas xadrez, chapéu de feltro ou couro e botas de couro de cano alto. Sobre as festas de rodeio ver Pimentel, 1997 apud Vidal e Souza, 1999.
Essa inversão da estética corporal da quadrilha estilizada implica uma mudança radical de perspectiva no olhar dirigido para o "homem rural", que não é mais necessariamente considerado uma pessoa simples de poucos recursos, mas alguém em harmonia com a produção, o mercado e a modernidade. Esse "novo homem rural" pode se inserir com naturalidade no meio urbano, o qual não é mais percebido como um espaço politicamente e simbolicamente inacessível, mas como um centro dinâmico, a cuja "immage favorable [...] s'oppose celle de la campagne dont le développement est toujours en retard" (Castigliani, 1989, p.16-17).

Um dos aspectos mais reveladores dessa releitura do personagem junino é o fato de ele ser majoritário em grupos de dança originários do interior, vindo se apresentar na capital por ocasião dos grandes concursos de quadrilha (que opõe os grupos da capital e do interior). Outro aspecto interessante é que o surgimento desses grupos não propôs o desaparecimento do estilo matuto. Sua expressão tampouco comportou uma revolução acerca do discurso hegemônico sobre o rural, o interior ou o sertão, pois ela não renovou o sentido, mas a forma da representação citadina do "matuto". Se essa nova interpretação dos símbolos, instituições e valores ligados ao São João propõe uma nova imagem do homem rural e do migrante, resta saber quem são os reformadores dessa tradição, onde vivem e que setores sociais eles representam.

\section{Grupos estilizados e identidade socioeconômica}

Além das implicações estéticas e políticoideológicas já discutidas aqui, a distância que se aprofunda com a constituição desse novo modelo de dança revela as tensões cotidianas relacionadas à inserção socioeconômica de seus habitantes.

Resumindo o processo de ocupação da cidade desde o início do século, observamos que a grande maioria dos migrantes de internos habita as periferias da cidade, reproduzindo um dinamismo ocupacional urbano que não é exclusivo de Natal. As diversas regiões da cidade, hoje dividida em quatro zonas (norte, sul, leste e 
oeste), concentram assim diferentes "fases" migratórias, podendo-se afirmar que, quanto mais central for a região - ou seja, quanto mais perto da área de fundação da cidade - mais antiga é a relação de seus habitantes com a migração. Considerando que Natal tinha pouco mais de 16 mil habitantes no final do século XIX, e pouco mais de 30 mil em 1920 (Cascudo, 1980, p. 7677), o primeiro grande fluxo migratório interno ocorreu nos anos 1940, quando a cidade atingiu 65 mil habitantes (Souza, 1981). Mas a cidade recebeu uma maior afluência de migrantes nos anos 1970, quando serão construídos grandes conjuntos habitacionais em setores afastados do centro da cidade, no que hoje se conhece por zona norte, mas também na zona oeste.

Separada do centro pelo principal rio da cidade, o Potengy, a zona norte, especialmente, concentra atualmente toda uma série de representações pejorativas sobre a periferia, sendo discriminada por pretensamente abrigar o perigo e a violência urbanos. Ora, o que nos interessa reter é que a grande maioria dos trabalhadores urbanos de Natal vive nesse setor da cidade, concentrando uma considerável quantidade de jovens e adultos economicamente ativos e atuantes na dinâmica econômica da cidade.

De fato, durante nossa pesquisa de campo, ${ }^{35}$ percebemos que a maioria dos grupos estilizados (75/93) está concentrada nas zonas norte, oeste e na Grande Natal, ${ }^{36}$ três setores marcados por uma ocupação territorial mais recente no contexto da capital do estado do Rio Grande do Norte. ${ }^{37}$ Sendo as zonas norte e oeste majoritariamente ocupadas por uma juventude desfavorecida-elas representam os dois setores mais pobres da cidade, com média de renda familiar inferior a cinco salários mínimos (Borges \& Ferreira, 1987, apud Martin, 1998, p. 360)-,

35. Realizada em 2001, junto a um concurso de quadrilha no qual observamos 114 grupos entre estilizados e tradicionais (VII Festival de Quadrilhas, promovido pela Televisão Cabugi) de diversos municípios do Rio Grande do Norte. Para uma análise sobre os concursos de quadrilha e a dinâmica competitiva/ identitária em Natal, ver Chianca, 2004.

36. A Grande Natal abarca alguns municípios vizinhos que guardam com Natal uma relação de interdependência econômica, como Parnamirim e São Gonçalo do Amarante por exemplo.

37. Trinta e quatro da zona norte, vinte e um da zona oeste e vinte da zona leste. como explicar sua grande adesão ao modelo estilizado da quadrilha, que é muito mais oneroso $^{38}$ e de difícil execução?

Sem desejar reificar a distinção norte/sul, bastante freqüente no discurso quotidiano dos moradores de Natal, é interessante salientar como esses dois setores da cidade comportam exemplos emblemáticos dessa relação: se a zona norte foi um dos últimos espaços de ocupação migrante pobre de Natal, em 2001 ela fornecia mais de 1/3 dos grupos de competição concorrendo num grande concurso televisivo, sendo 20 estilizados e 14 matutos.

A zona sul tem outra configuração socioeconômica, não no que se refere à origem dos seus habitantes ou de seus genitores, mas relativamente a sua assimilação citadina no presente, já que sua ocupação apresenta uma população bem mais favorecida. Migrantes de boa condição econômica desde o início do processo, ou encontrando "sucesso" na migração, eles se interessam e praticam mais o estilo matuto. Sua população permanece quase indiferente a esses festivais e à modalidade competitiva da dança (cinco grupos inscritos, sendo quatro matutos em 2001).

Acreditamos que a experiência migratória citada - mais ou menos recente - e a inserção socioeconômica constituem dados decisivos para a escolha desses grupos, guardando uma interdependência íntima com suas dinâmicas identitárias. A predominância de um ou outro estilo de quadrilha de competição guarda, então, forte relação entre a antigüidade da presença trabalhadora migrante e seu grau de integração citadina.

\section{Conclusão: entre integração e assimilação}

Os estereótipos dominantes do migrante veiculados pelo modelo tradicional explicam a razão dessas escolhas, associadas a uma forte motivação de integração da juventude dos bairros pobres de Natal. Para os grupos de

38. A título indicativo, em 2001 uma roupa completa de matuta custava entre $\mathrm{R} \$ 100,00$ e $\mathrm{R} \$ 150,00$, enquanto o de uma dançarina estilizada custava o triplo. O valor de uma roupa é muito variado segundo o "papel" do componente, o material empregado e a mão-de-obra de sua confecção, mas é determinado pela quadrilha. O dançarino apenas acata a escolha dos dirigentes acerca desses aspectos (ver Chianca, 2004). 
quadrilha de competição, não se trata somente de uma referência à identidade das origens, mas também e sobretudo de reconstruir sua identidade citadina presente, como cidadãos plenamente assimilados pela sua cidade, extrapolando as referências habituais fortemente estigmatizadas da sua "zona", "bairro", "conjunto" e grupo social. Além da dinâmica identitária aí inscrita, quais são os interesses mais amplos que esses concursos mobilizam, ou melhor: por que eles atraem tantos grupos de quadrilha?

Ora, pela sua própria situação de mediação na experiência migratória, (citadinos, filhos ou netos de migrantes), eles estão mais aptos a responder ao desafio da assimilação citadina, tanto no plano socioeconômico quanto simbólico. As quadrilhas estilizadas representam uma tentativa dessa natureza. Apenas uma análise pluridimensional da dança junina poderá integrar a relação entre rural/urbano, folclore/globalização cultural, cotidiano/festa; três feixes de significados que compõem os projetos identitários em jogo nas quadrilhas juninas contemporâneas de Natal.

Resumé: Nous présenterons ici quelques expressions symboliques de la mise à jour de l'identité citadine du migrant, parmi des jeunes brésiliens d'origine socioéconomique défavorisée. Ce processus peut être perçu par l'observation de l'un des plus importants rituels de la fête de la saint-Jean urbaine de Natal, les quadrilhas de la saint-Jean, aussi bien dans sa prestation traditionelle que dans sa nouvelle version connue comme "stylisée". Tout en réfusant reprendre l'image stéreotypée du caipira renforcée par l'éternel "Jeca Tatu" de M. Lobato -, ces fils de migrants préferent se présenter tels des "matutos de luxe", habillés en soie, velours et satin. Comment cette nouvelle production d'identité est-elle perçue par ses acteurs et par l'ensemble de la société?

Mots-clé: identité; migration; fête; caipira; matuto.

\section{Referências}

ALMEIDA , Magdalena (Dir.) Quadrilha junina história e atualidade, um movimento que não é só imagem. Recife: Fundação de Cultura da Cidade do Recife, 2001.

ANDRADE, Mario de. Dicionário musical brasileiro. Belo Horizonte/ São Paulo: Itatiaia/Edusp, 1989. AUGE, Marc. Les formes de l'oubli . Paris: Ed. Payot et Rivages, 2001.
AZZI, Riolando. O catolicismo popular no Brasil. Petrópolis: Vozes, 1978.

BERNARDO, Teresinha. Memória como resistência. Travessia, n. 32, set.-dez./1998, Centro de Estudos Migratórios. São Paulo, 1998. p. 44-45.

BRUN, André. Les dieux catholiques au Brésil. Paris: Harmattan, 1989.

CANDIDO, Antonio. Os parceiros do Rio Bonito. São Paulo: Livraria Duas Cidades, 1987.

CARNEIRO, Sandra M. C. S. Balão no céu, alegria na terra. Rio de Janeiro: Ed. Funarte/INF, 1986.

CARNEIRO, Edison. Antropologia e folclore. Revista Brasileira do Folclore, ano I, n. 1, set./dez. 1961. Rio de Janeiro: Ed. Itambé, 1961. p. 81-85.

Congresso Internacional de Folclore de Buenos Aires. Revista Brasileira do Folclore, ano I, n. 1, set./dez. 1961. Rio de Janeiro: Ed. Itambé, 1961b. p. 85-86.

CASCUDO, Luis da Câmara. Da cultura popular. Revista Brasileira de Folclore. ano I, n. 1, set./dez 1961. Ministério da Educação e Cultura.

. História da cidade do Natal. UFRN. 2. ed.

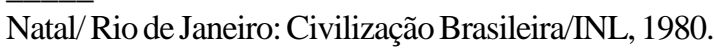

CASTIGLIONI, Aurélia H. Migration, urbanisation et développement: le cas de Espirito Santo - Brésil. Bruxelles: Ciaco éditeurs, 1989.

CAVIGNAC, Julie. La littérature de colportage au Nord-Est du Brésil. Paris: CNRS, 1997.

Reconstruindo o passado: memória de migrantes da zona norte de Natal. Travessia, n. 32, set.-dez./1998, Centro de Estudos Migratórios, São Paulo. P. 35-40.

CHEVALIER, Jean \& GHEERBRANT, Alain. Dictionnaire des symboles. 16. ed. Paris: Ed. Robert Laffont S.A. Ed. Jupiter, 1994.

CHIANCA, Luciana. A festa do interior: São João, migração e nostalgia em Natal no século XX. Natal: EdUFRN, 2006.

Autres feux, autres lieux: quadrilhas de la Saint-Jean, migration et identité à Natal (Rio Grande do Norte), Brésil. Bordeaux, 2004. Thèse (Doctorat en ethnologie) - Université Bordeaux 2.

Quadrilhas juninas. Galante, n. 1, ano 3, vol. II, junho 2001. Fundação Hélio Galvão, Natal.

. Para onde vai a cidade? Festa junina em Natal-RN. Vivência, vol. 13, n. 1, EdUFRN, UFRN, Natal, 1999. p. 55-69.

CORDEIRO, Graça I. Bairros: contexto e intersecção. In: VELHO, Gilberto. (Org.). Antropologia urbana: cultura e sociedade no Brasil e em Portugal. Rio de Janeiro: Jorge Zahar Ed, 1999. 
DOMENACH, Hervé \& PICOUET, Michel. Les migrations. Paris: Ed P.U.F., 1995. [Collection Que sais-je?]

DUVIGNAUD, Jean. Fêtes et civilisations et Fêtes aujourd'hui. France: Actes Sud, 1991.

FERRÃO, Euzalina da Silva et alli. Um folclore renovado: uma análise sobre as quadrilhas "roceiras" de Belém e a política cultural institucional. Belém: UFPA, s/d. [Mimeo.]

GRUNSPAN- JASMIN, Elise. Lampião: Vies et morts d'un bandit brésilien. Paris: Le Monde/PUF, 2001.

GURGEL, Deífilo. Espaço e tempo do folclore potiguar. Natal: Prefeitura de Natal, Funcart, Secretaria do $4{ }^{\circ}$ Centenário, 1999.

HOLANDA FERREIRA, Aurélio Buarque de. Novo dicionário Aurélio da língua portuguesa. Rio de Janeiro: Nova Fronteira, 1999.

JESUS E SILVA FILHO, Thadeu. Festa junina e Brasília: que relação é essa ? Pos: Revista Brasiliense de pós-graduação em Ciências Sociais, ano 2, n. 1, Ed. Katacumba, Brasília, 1998. p. 7-29.

JORNALA TARDE, Salvador (BA).

JORNAL O POTY, Natal (RN).

JORNAL TRIBUNADO NORTE, Natal (RN).

LÉVI-STRAUSS, Claude. Anthropologie structurelle. Paris: Plon, 1974.

L'identité. Paris: Quadrige/P.U.F., 1995.

LIMA, Elisabeth Christina de Andrade. A fábrica dos sonhos: a invenção da festa junina no espaço urbano. João Pessoa: Idéia, 2002.

LINS, Osman. Ao pé da fogueira. In: Do ideal e da glória: problemas indoculturais brasileiros. São Paulo: Ed. Summus, 1977. p. 157-156.

LOBATO, Monteiro. Problema vital. São Paulo: Ed. Brasiliense, 1955.

Jecatatuzinho. Biotônico Fontoura, s/l, 1957.

MARTIN, Jean-Yves. Identités et territorialités dans le Nordeste brésilien: le cas du Rio Grande do Norte. Bordeaux, 1998. Thèse (Doctorat) - Université Bordeaux III.

MARTINS, José de Souza. Capitalismo e tradicionalismo. São Paulo: Livraria Pioneira Editora, 1975.

Migrações temporárias: problema para quem? Travessia, n. 1, mai.-ago./1988, Centro de Estudos Migratórios, São Paulo. P. 5-8.

MELLO MORAIS FILHO, Alexandre José de. Festas e tradições populares no Brasil. Belo Horizonte/ São Paulo: Itatiaia/Edusp, 1979.
MENEZES, Maria Aparecida de et alli. O retorno para a festa. Travessia, n. 7, ano III, mai.-ago./1990, Centro de Estudos Migratórios, São Paulo.

MENEZES, Maria Aparecida de. Redes e enredos nas trilhas dos migrantes: um estudo de famílias de camponeses migrantes. João Pessoa/Rio de Janeiro: EDUFPB/Relume Dumará, 2002.

MONTEIRO LOBATO. Disponível em: www.lobato. com.br

MORICE, Alain. Une légende à revoir: l'ouvrier du bâtiment brésilien sans feu ni lieu. Identités spatiales et urbanisation: Asie, Afrique, Amérique. Cahiers de Sciences Humaines, vol. 29, n. 2-3, Ed. de l'Orstom Paris, 1993. p. 349-371.

MOURA, Carlos Eugênio Marcondes de. O teatro que o povo cria. Belém: Secult, 1997.

MUZART- FONSECA DOS SANTOS, Idelette. $L a$ littérature de cordel au Brésil. Paris: Editions Harmattan, 1997.

OFFNER, Jean-Marc \& PUMAIN, Denise (Dir.). Réseaux et territoires: significations croisées. France: Éditions de l'Aube, 1996.

ORTIZ, Renato. Românticos e folcloristas. São Paulo: Ed. Olho d'água, 1992.

PINHO, Wanderley. Salões e damas no Segundo Reinado. São Paulo: Livraria Martins, s/d.

PRADO, Regina de Paula Santos. Todo ano tem: as festas na estrutura social camponesa. Rio de Janeiro, 1977. Dissertação (Mestrado) - Museu Nacional.

PREFEITURA MUNICIPAL DE NATAL. Disponível em: www.natal.rn.gov.br/sempla/paginas/ estatisticas/informacoes.php. Acesso em: 28/8/06.

RIBAS, Tomaz. Danças populares portuguesas. Portugal: Instituto de Cultura e Língua Portuguesa, Ministério da Educação, 1983.

RIGAMONTE, Rosani Cristina. Severinos, Januárias e Raimundos. In: Na metrópole. São Paulo: Edusp, 1996. p. 230-251.

. A Praça Silvio Romero: a tradição. Travessia, ano XII, n. 35, Centro de Estudos Migratórios, São Paulo, 1999. p. 37-42.

SALLAS, Ana Luisa Fayet. Etnografia do sertão country. In: Anuário antropológico 97. Rio de Janeiro: Tempo Brasileiro, 1999. p. 351-361.

SILVA, Silvano Alves Bezerra da. A pedagogia de Chico Bento: o caipira e seu universo no discurso das histórias em quadrinhos. João Pessoa, 1998. 
Dissertação (Mestrado em Ciência da Informação) UFPB.

SOUZA, Itamar de. Migrações internas no Brasil. Natal/Petrópolis: Ed. Fundação José Augusto/Ed. Vozes, 1980.

O compadrio: da política ao sexo. Natal/ Petrópolis: Fundação José Augusto/Vozes, 1981.

VIDAL E SOUZA, Candice. O sertão de boiadeiro. In: Anuário antropológico 97. Rio de Janeiro: Tempo Brasileiro, 1999. p. 343-360.
VILHENA, Luis Rodolfo. Projeto e missão: o movimento folclórico brasileiro, 1947-1964. Rio de Janeiro: Funarte/Fundação Getulio Vargas, 1997.

YATSUDA, Enid. O caipira e os outros. In: BOSI, Alfredo (Org.). Cultura brasileira: temas e situações. São Paulo: Ed. Ática, 1987.

ZALUAR, Alba. Os homens de Deus: les saints et ses fêtes au catholicisme populaire. Rio de Janeiro: Zahar, 1983. 